\title{
The Circulating Transcriptome as a Source of Biomarkers for Melanoma
}

\author{
Carla Solé ${ }^{1}$, Daniela Tramonti ${ }^{2}$, Maike Schramm ${ }^{1,3}$ D, Ibai Goicoechea ${ }^{1}$, María Armesto ${ }^{1}$, \\ Luiza I. Hernandez ${ }^{1}$ D, Lorea Manterola ${ }^{1}$, Marta Fernandez-Mercado ${ }^{1}$ (D, Karmele Mujika ${ }^{4}$, \\ Anna Tuneu ${ }^{5}$, Ane Jaka ${ }^{5}\left(\mathbb{D}\right.$, Maitena Tellaetxe ${ }^{1}(\mathbb{D}$, Marc R. Friedländer 6,7,8,9,10, \\ Xavier Estivill 6,7,8,9 , Paolo Piazza 11,12, Pablo L. Ortiz-Romero 13,14 ${ }^{\mathbb{D}}$, Mark R. Middleton ${ }^{2} \mathbb{D}$ \\ and Charles H. Lawrie $1,15,16, *$
}

1 Molecular Oncology group, Biodonostia Research Institute, San Sebastián 20012, Spain; carla.sole@biodonostia.org (C.S.); m.schramm02@googlemail.com (M.S.); ibai.goicoechea@biodonostia.org (I.G.); maria.armesto@biodonostia.org (M.A.); luiza.hernandez@liu.se (L.I.H.); lorea.manterola@biodonostia.org (L.M.); marta.fernandez@biodonostia.org (M.F.-M.); maitena.tellaeche@biodonostia.org (M.T.)

2 Department of Oncology, University of Oxford, Oxford OX3 9DU, UK; dtramonti@hotmail.com (D.T.); mark.middleton@oncology.ox.ac.uk (M.R.M.)

3 Faculty of Biosciences, University of Heidelberg, Heidelberg 69120, Germany

4 Onkologikoa-Oncology Institute Gipuzkoa, Gipuzkoa 20012, Spain; kmujika@onkologikoa.org

5 Department of Dermatology, Hospital Universitario de Donostia, San Sebastian 20012, Spain; annadonosti@gmail.com (A.T.); iratzia@hotmail.com (A.J.)

6 Genomics and Disease group, Centre for Genomic Regulation (CRG), Barcelona 08003, Spain; marc.friedlander@scilifelab.se (M.R.F.); xavier.estivill@crg.es (X.E.)

7 Universitat Pompeu Fabra (UPF), Barcelona 08002, Spain

8 Centro de Investigación Biomédica en Red Epidemiología y Salud Pública (CIBERESP), Barcelona 08002, Spain

9 Hospital del Mar Research Institute (IMIM), Barcelona 08003, Spain

10 Science for Life Laboratory, The Wenner-Gren Institute, Stockholm University, Stockholm SE-106 9, Sweden

11 Wellcome Trust Centre for Human Genetics, University of Oxford, Oxford OX3 7BN, UK; p.piazza@imperial.ac.uk

12 Imperial BRC Genomics Facility, Imperial College London, London SW7 2AZ, UK

13 Department of Dermatology, 12 de Octubre Hospital, Madrid 28041, Spain; pablo.ortiz@salud.madrid.org

14 Medical School, Universidad Complutense, Institute i+12, Centro de Investigación Biomédica en Red en Oncologia (CIBERONC), Madrid 28040, Spain

15 Radcliffe Department of Medicine, University of Oxford, Oxford OX3 9DU, UK

16 IKERBASQUE, Basque Foundation for Science, Bilbao 48013, Spain

* Correspondence: charles.lawrie@biodonostia.org

Received: 15 November 2018; Accepted: 4 January 2019; Published: 10 January 2019

\begin{abstract}
The circulating transcriptome is a valuable source of cancer biomarkers, which, with the exception of microRNAs (miRNAs), remains relatively unexplored. To elucidate which RNAs are present in plasma from melanoma patients and which could be used to distinguish cancer patients from healthy individuals, we used next generation sequencing (NGS), and validation was carried out by qPCR and/or ddPCR. We identified 442 different microRNAs in samples, eleven of which were differentially expressed $(p<0.05)$. Levels of $m i R-134-5 p$ and $m i R-320 a-3 p$ were significantly down-regulated $(p<0.001)$ in melanoma samples $(n=96)$ compared to healthy controls $(n=28)$. Differentially expressed protein-encoding mRNA 5'-fragments were enriched for the angiopoietin, p21-activated kinase (PAK), and EIF2 pathways. Levels of ATM1, AMFR, SOS1, and CD109 gene fragments were up-regulated $(p<0.001)$ in melanoma samples $(n=144)$ compared to healthy controls $(n=41)($ AUC $=0.825)$. Over $40 \%$ of mapped reads were YRNAs, a class of non-coding RNAs that to date has been little explored. Expression levels of RNY3P1, RNY4P1, and RNY4P25 were
\end{abstract}


significantly higher in patients with stage 0 disease than either healthy controls or more advanced stage disease $(p<0.001)$. In conclusion, we have identified a number of novel RNA biomarkers, which, most importantly, we validated in multi-center retrospective and prospective cohorts, suggesting potential diagnostic use of these RNA species.

Keywords: melanoma; plasma; liquid biopsy; miRNA; mRNA; biomarker; YRNA; RNA species

\section{Introduction}

Although malignant melanoma accounts for $\sim 4 \%$ of skin cancer cases, it accounts for $\sim 75 \%$ of all associated mortalities. In the US alone, it is estimated there were 87,000 new cases and nearly 10,000 deaths due to melanoma in 2017 [1]. Furthermore, the incidence of melanoma has been increasing at faster rate than any other cancer type, having doubled since 1973 [2]. The clinical case for early diagnosis of melanoma is compelling, as if detected early enough, (stage I) 5 year survival is $>95 \%$, whereas in advanced melanoma (stage IV) survival is just 10-20\% [3].

Non-invasive diagnostics, or liquid biopsies, represent a major advance towards earlier diagnosis and disease monitoring of cancer patients, including those with melanoma. As a consequence, there has been a great deal of interest in recent years in the potential of circulating nucleic acids, and in particular circulating microRNAs (miRNAs) [4,5]. In melanoma, several studies have implemented circulating miRNA in metastasis and risk of recurrence [6,7]. However, outside of miRNAs there has been little research on other cell-free (cf) RNA species in the circulating transcriptome. Part of the reason for this paucity of knowledge is the presence of high levels of RNase activity in blood, which typically results in fragmentation of longer RNA species such as mRNA [8,9]. This makes detection of these molecules particularly challenging. The advent of next-generation sequencing (NGS) technology, however, presents new opportunities for the field, as sequences can be elucidated in a 'bottom-up' manner without the need of a priori probe sequence knowledge. We used next generation sequencing (NGS) to characterize and compare the circulating transcriptomes of plasma from melanoma patients with different stage disease, along with sex-/age-matched healthy individuals, in order to identify novel biomarkers for this cancer.

We identified not only circulating miRNAs with biomarker potential, but also mRNA gene fragments and non-coding YRNAs. YRNAs (Ro-associated $Y$ ) are poorly characterized, non-coding RNAs, which were initially identified in the blood of rheumatic autoimmune disease patients [10]. They are a family based around four highly conserved sequences (RNY1, RNY3, RNY3, RNY5) involved in Ro60 inhibition, DNA replication, and quality control of non-coding RNAs [11-13]. Our possible biomarkers were validated in an independent cohort of 327 plasma samples from melanoma patients, collected retrospectively and prospectively. This study provides evidence that the largely unexplored circulating transcriptome could provide a valuable source of liquid biopsy biomarkers for melanoma in particular, and cancer in general.

\section{Results}

\subsection{Sequencing the Circulating Transcriptome of Melanoma Patients}

We optimized library construction by comparing several protocols, including different ribodepletion methodologies, using plasma from healthy controls in a pilot study, before settling on the protocol described in materials and methods [14]. It should be noted, however, that this protocol might result in some ligation-based bias [15]. Using this protocol, we sequenced cfRNA derived from plasma of melanoma patients, along with age-/sex-matched controls (Table 1).

Due to the low quantity of cfRNA in plasma, we decided to pool plasma samples according to clinical stage, as depicted in Table 1. For each pooled sample, 40-50 million reads were obtained, 
with an average Phred score of 37.9 (Supplementary Table S1). Between 50-55\% of reads were mapped to the human genome (hg19), and approximately half of these sequences were considered small RNA (sRNA), representing sequences between 18-43 nt (Supplementary Table S1; Figure 1a). By far the largest category by frequency of reads was YRNAs, accounting for an average of $40.6 \%$ of reads (range 34-48\%; Figure 1). Indeed, this category accounted for $>95 \%$ of reads that composed the major peak at $32 \mathrm{nt}$ seen in the size profiles of samples (typical example shown in Figure 1a).

a
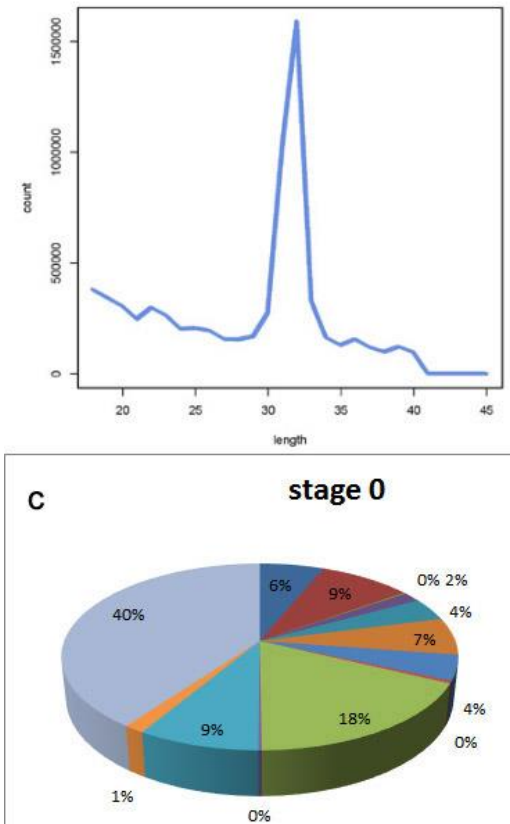

b

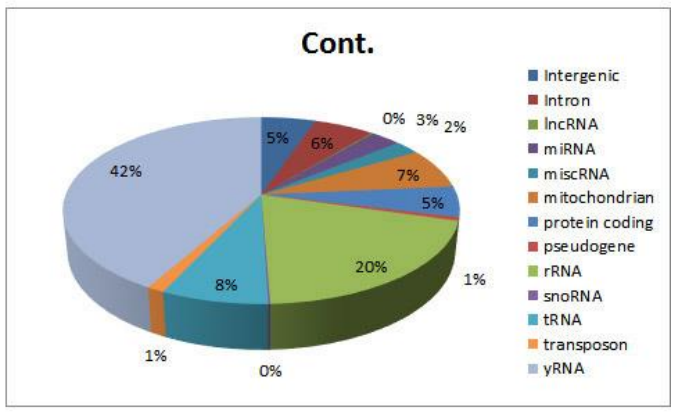

d
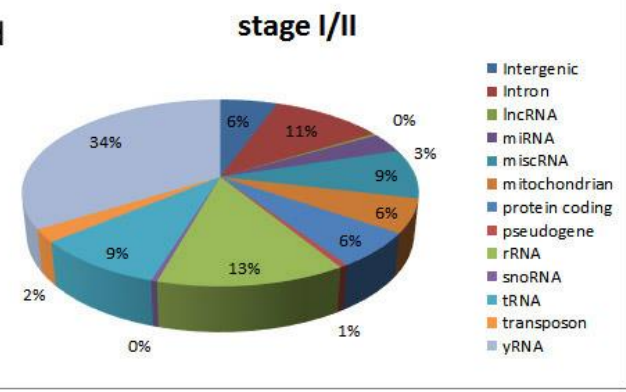
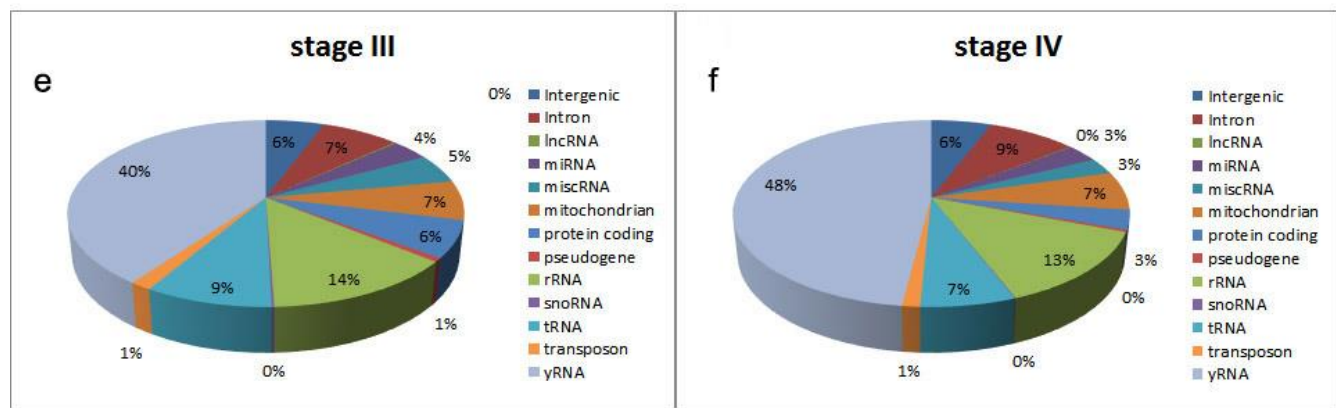

Figure 1. RNAseq results from circulating transcriptome. (a) Typical length-frequency of obtained reads in library. Proportion of reads mapping to different categories of sRNA for (b) control pool, (c) stage 0 pool, (d) stage I/II pool, (e) stage III pool, (f) stage IV pool.

Table 1. Summary of clinical details of patient cohorts used in study. NK: not known.

\begin{tabular}{ccccc}
\hline & Stage & $\boldsymbol{n}$ & Age (Median) & Sex (M/F/(NK)) \\
\hline \multirow{5}{*}{ NGS cohort } & Control & 8 & 58 & $4 / 4$ \\
& Pool 0 & 5 & 76 & $3 / 2$ \\
& Pool I/II & 8 & 63 & $4 / 4$ \\
& Pool III & 8 & 68 & $3 / 5$ \\
& Pool IV & 8 & 59 & $3 / 5$ \\
\hline
\end{tabular}


Table 1. Cont.

\begin{tabular}{ccccc}
\hline & Stage & $\boldsymbol{n}$ & Age (Median) & Sex (M/F/(NK)) \\
\hline \multirow{2}{*}{ mRNA } & Control & 47 & 54 & $18 / 23$ \\
validation cohort & Stage 0 & 34 & 64 & $11 / 17 /(1)$ \\
& Stage I/II & 52 & 58 & $19 / 25$ \\
& Stage III/IV & 87 & 57.5 & $32 / 37 /(2)$ \\
\hline \multirow{3}{*}{ miRNA } & Control & 28 & 58 & $12 / 14 /(2)$ \\
validation cohort & Stage 0 & 29 & 51 & $6 / 19 /(4)$ \\
& Stage I/II & 33 & 60 & $10 / 14 /(9)$ \\
& Stage III/IV & 34 & 55 & $11 / 15 /(8)$ \\
\hline \multirow{2}{*}{ YRNA } & Control & 22 & 57.5 & $11 / 11 /$ \\
validation cohort & Stage 0 & 20 & 51 & $11 / 5 /(4)$ \\
& Stage I/II & 17 & 48 & $9 / 8$ \\
& Stage III/IV & 21 & 61 & $\mathbf{1 7 5 / 2 2 1 / ( 3 0 )}$ \\
\hline
\end{tabular}

\section{2. miRNA Expression}

We detected 442 different human miRNA sequences in the samples, which accounted for between $1.38 \times 10^{5}$ and $3.14 \times 10^{5}$ reads per sample. The most abundant miRNAs were members of the let-7 family, which accounted for $>70 \%$ of mapped miRNAs reads, followed by miR-423 and miR-320a-3p. Eleven miRNAs were identified by ANOVA as being differentially expressed between the different disease stages and healthy controls ( $p<0.05,>50$ reads per sample; Table 2$)$. We measured levels of the four most differentially expressed miRNAs (miR-134-5p and miR-320a-3p, miR-21-5p and miR-92b-3p) by qRT-PCR plasma samples in 28 healthy controls and 96 melanoma patients (Table 1). We were unable to detect miR-21-5p and miR-92b-3p [16].

Table 2. Differentially expressed microRNAs (miRNAs) $(p<0.05)$. Counts were normalized per million reads. miRNAs validated are depicted in bold.

\begin{tabular}{ccccccc}
\hline miRNA & Cont. & Stage 0 & Stage I/II & Stage III & Stage IV & $p$-Value \\
\hline miR-134-5p & 7474 & 7290 & 2293 & 4200 & 4876 & 0.0158 \\
miR-320a-3p & 117,411 & 76,952 & 56,705 & 86,933 & 74,154 & 0.0181 \\
miR-21-5p & 356 & 405 & 368 & 782 & 469 & 0.0183 \\
miR-92b-3p & 14 & 14 & 20 & 25 & 51 & 0.0232 \\
miR-98-5p & 9850 & 12,999 & 9124 & 14,243 & 13,627 & 0.0232 \\
miR-16-3p & 21 & 29 & 49 & 39 & 53 & 0.0277 \\
Let-7b & 385 & 507 & 326 & 267 & 396 & 0.0286 \\
miR-1827 & 58 & 28 & 7 & 7 & 11 & 0.0375 \\
miR-1180 & 107 & 145 & 49 & 45 & 42 & 0.0392 \\
miR-628 & 499 & 667 & 375 & 502 & 407 & 0.0496 \\
miR-486 & 4581.23 & 6014.45 & 1501.33 & 2704.89 & 1879.67 & 0.0497 \\
\hline
\end{tabular}

Consistent with the NGS data, we found that miR-134-5p and miR-320a-3p were significantly down-regulated in patients compared to controls (Figure 2a,b). Levels of these miRNAs were lower in stage 0 patients than in healthy controls, and even lower in stage I/II patients $(p<0.05)$. Receiver operating characteristic (ROC) analysis gave area under curve (AUC) values of 0.798 (miR-320a-3p) and 0.788 (miR-134-5p), with a higher sensitivity (90\%) for miR-320a-3p and a higher specificity for miR-134-5p (96\%) (Figure 2c,d and Table 3). 
Table 3. ROC analysis values of expression levels of differentially expressed miRNAs and gene fragments. * AUC values of different stage vs. control sample. Panel was a combination of ATM, AMFR, and SOS1.

\begin{tabular}{cccccccc}
\hline Probe & AUC & Sensitivity & Specificity & $\mathbf{9 5 \%}$ CI & $\mathbf{0}^{*}$ & I/II * & III/IV $^{*}$ \\
\hline miR-320a-3p & 0.798 & $90 \%$ & $61 \%$ & $0.712-0.869$ & 0.751 & 0.870 & 0.828 \\
miR-134-5p & 0.788 & $55 \%$ & $96 \%$ & $0.704-0.858$ & 0.680 & 0.868 & 0.811 \\
ATM & 0.767 & $61 \%$ & $72 \%$ & $0.697-0.829$ & 0.769 & 0.734 & 0.715 \\
AMFR & 0.748 & $52 \%$ & $92 \%$ & $0.676-0.812$ & 0.822 & 0.709 & 0.641 \\
CD109 & 0.753 & $54 \%$ & $90 \%$ & $0.680-0.816$ & 0.816 & 0.706 & 0.702 \\
SOS1 & 0.772 & $48 \%$ & $95 \%$ & $0.699-0.835$ & 0.796 & 0.694 & 0.693 \\
Panel & 0.825 & $75 \%$ & $92 \%$ & - & - & - & - \\
\hline
\end{tabular}

a

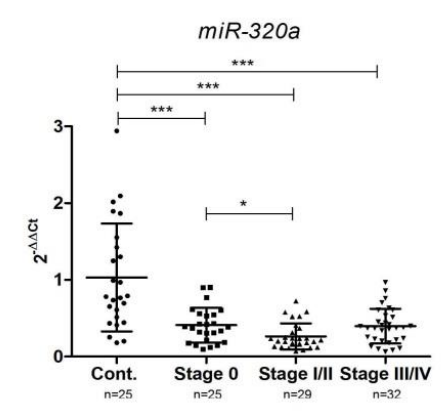

C

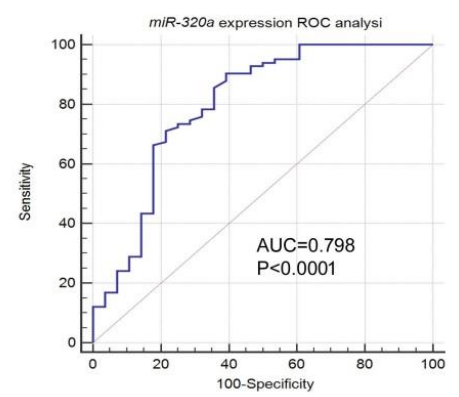

b

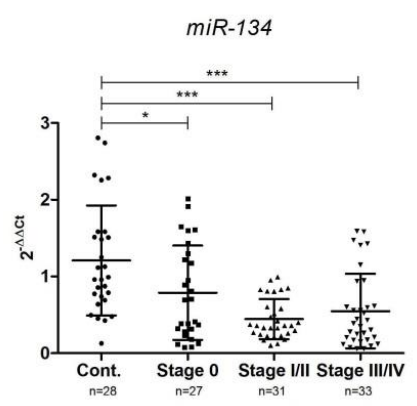

d

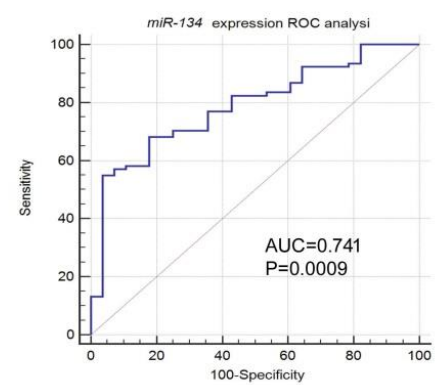

Figure 2. Expression levels of miRNAs measured by qRT-PCR in independent validation cohorts. $(\mathbf{a}, \mathbf{b})$ Levels of $m i R-320 a$ and $m i R-134$ were measured in a cohort of 124 plasma samples (28 controls and 96 melanoma patients). Expression levels were compared using the Kruskal-Wallis multiple comparison test (both miR-134 and miR-320a had $p$-values of <0.0001) and the Mann-Whitney independent $t$-test to carry out a pairwise comparison between groups $\left({ }^{*} p<0.5 ;{ }^{* * *} p<0.001\right)(\mathbf{c}, \mathbf{d})$ ROC analysis of miRNA probe expression levels as diagnostic biomarker (i.e., control vs. all melanoma patients, regardless of stage).

\section{3. mRNA Fragment Expression}

Because mRNA is degraded by RNase activity in the blood into fragments with an average size of 200 bases [8], rather than mapping reads to whole genes or exons, we mapped them to short annotated probe sets ( $<500$ bases). There were 3672 different probe sets (median length of $244 \mathrm{nt}$ ), with greater than 25 reads per probe set mapping to 13,641 different transcripts. For each probe set we analyzed their relative position within the respective transcripts as a percentage of the entire transcript length. By far the largest proportion (5350/13641 (39\%)) of probe sets mapped to the first decile (10\%) (i.e., $5^{\prime}$-end) of the transcript, compared to an average of $6 \%$ for the other nine deciles of the transcript length (Figure 3a). 
a

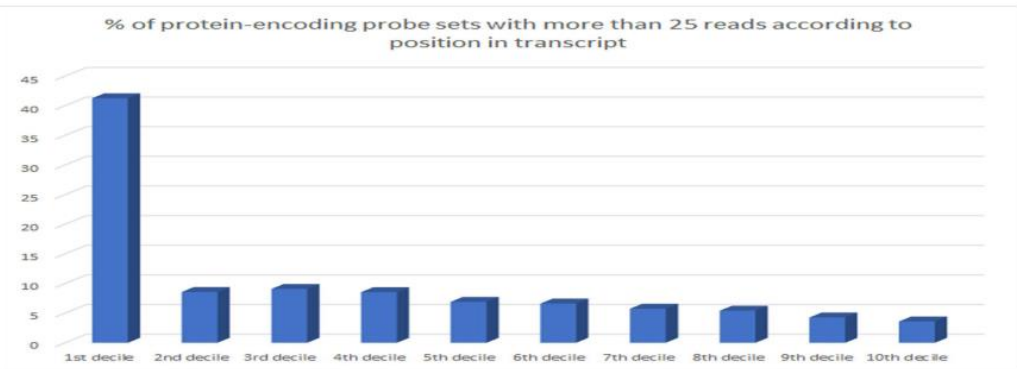

b
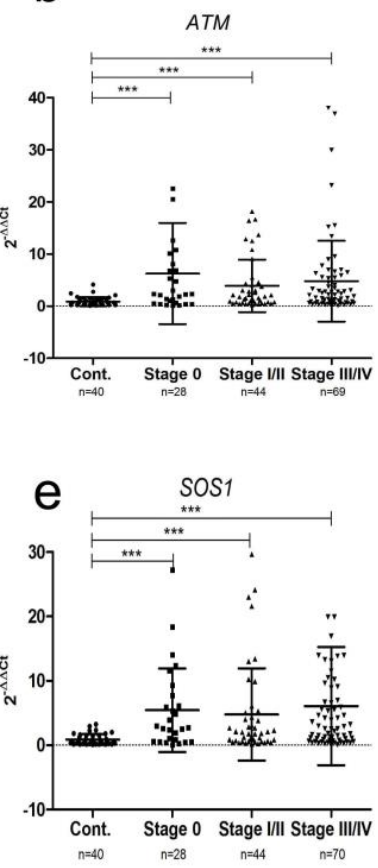

h

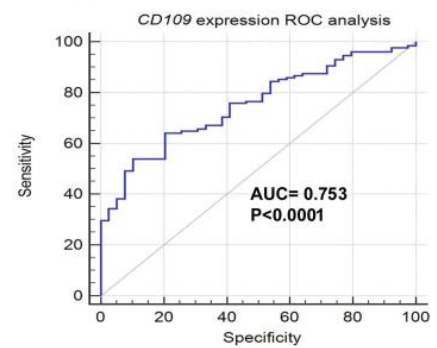

C

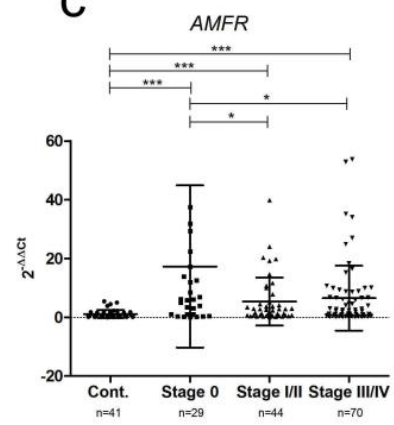

f

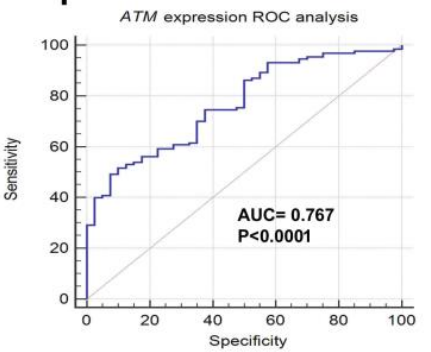

i

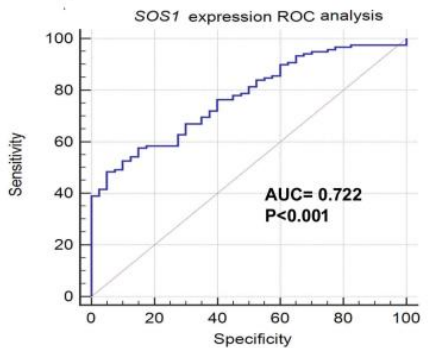

d

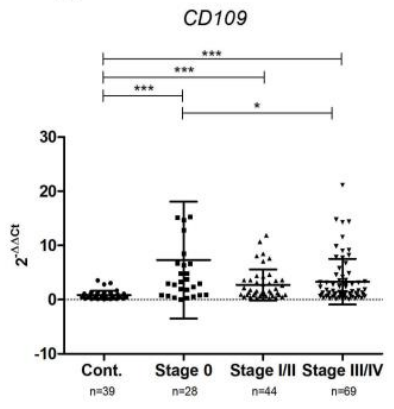

g

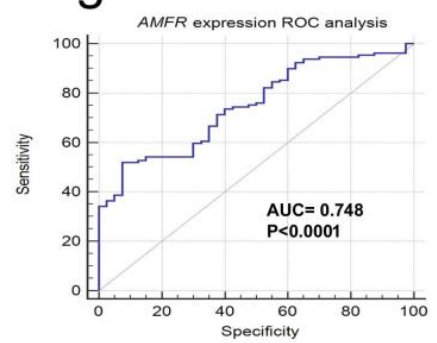

j

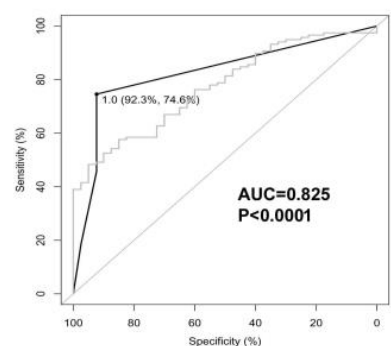

Figure 3. Expression levels of mRNA fragments measured by qRT-PCR in independent validation cohorts. (a) Proportions of probe sets containing at least 25 reads ( $>500$ bases in length) relative to their position ( $5^{\prime}$ to $3^{\prime}$ direction) along the respective transcript. (b-e) Levels of ATM, AMFR, CD109, and SOS1 probes were measured in a cohort of 185 plasma samples (41 controls and 144 melanoma patients). Levels are shown relative to the mean expression of the control sample cohort (i.e., $2-\Delta \Delta C \mathrm{t}$ ). Expression levels were compared using the Kruskal-Wallis multiple comparison test (all the mRNA fragments had $p$-values of $<0.0001$ ), and the Mann-Whitney independent $t$-test to carry out a pairwise comparison between groups $\left({ }^{*} p<0.5 ;{ }^{* * *} p<0.001\right)(\mathbf{f}-\mathbf{i})$ ROC analysis of mRNA probe expression levels as diagnostic biomarker (i.e., control vs. melanoma patient). (j) Panel (ATM, AMFR, and SOS1) performance shown with black line, and SOS1 is shown as a gray line for comparison. 
Seventy of the probe sets were identified as being differentially expressed between samples $(p<0.05$; Table A1). We designed custom Taqman probes to detect fragments from the five most differentially expressed probe sets (i.e., corresponding to ATM, ARHGAP, AMFR, CD109, and SOS1 genes) (Supplementary Table S2; Figure S1). We were unable to design a specific probe for the ARHGAP probe set due to a high level of repetitive sequences. None of the mRNAs validated are predicted targets of miRNAs studied (i.e., $m i R-134-5 p$ and $m i R-320 a$ ) using the predictive algorithms TargetScan and miRDB [17]. The four probe sets were measured by qRT-PCR in 47 control and 173 melanoma patient samples (Table 1).

Levels of ATM, AMFR, CD109, and SOS1 were all significantly higher $(p<0.001)$ in plasma samples from either stage 0 , stage I/II, or stage III/IV melanoma patients than in healthy controls (Figure 3b-e, respectively), consistent with the NGS data (Table A1). Surprisingly, levels of AMFR and CD109 were higher in plasma from stage 0 patients than samples with more advanced disease. We carried out ROC analysis to determine the diagnostic ability of the mRNA fragments (Table 3; Figure 3f-i), and to discriminate between different disease stages (Table 3; Supplementary Figure S2a-d). We looked at combinations of these biomarkers using the PanelomiX ROC comparison algorithm [18]. A combination of ATM, SOS1, and AMFR with cut-off values of 2.13, 2.96, and 2.26 respectively, gave the best diagnostic accuracy (AUC $=0.825)$ (Table 3, Figure 3j).

\subsection{YRNA Expression}

As nearly half of all mapped sRNA reads were identified as YRNA sequences (Figure 1), we examined this class of non-coding RNAs further. There were 322 different YRNA and YRNA-associated sequences identified in our samples, consisting of three YRNA sequences (RNY1, $R N Y 3$, and $R N Y 4$ ) representing an average of $26.1 \%$ of reads, 30 YRNA pseudogenes representing an average of $48.4 \%$ of reads, 69 7SK sequences (average $0.05 \%$ of reads), and 194 Rfam predicted YRNA sequences representing an average of $25.5 \%$ of reads (Supplementary Table S3). The vast majority of reads were represented by RNY4 and RNY4P sequences, accounting for $>98 \%$ of their respective YRNA class (Figure 4a).

We compared the expression of YRNAs between low-stage disease (i.e., stage 0 and I/II) and high-stage disease (i.e., stage III and IV), and identified five differentially expressed YRNA fragments $(p<0.05 ;$ Table 4$)$. We designed custom Taqman probes to measure three of these YRNAs (RNY3P1, $R N Y 4 P 1$, and RNY4P25), selected on the basis of fold-change and read count. We measured levels of the YRNAs in a validation cohort of 80 samples (22 controls and 58 melanoma patients, Table 1). Levels of all three YRNAs were significantly higher in stage 0 samples than control samples or stage I/II samples (Figure 4b-d).

Table 4. Differentially expressed YRNAs $(p<0.05)$. Counts were normalized per million reads. YRNAs validated are depicted in bold.

\begin{tabular}{ccccc}
\hline & Stage 0/I/II & Stage III/IV & Fold Change & $p$-Value \\
\hline RNY4P18 & 85 & 193 & 2.2 & 0.00033 \\
RNY3P1 & 86 & 210 & 2.4 & 0.00063 \\
RNY4P6 & 12,442 & 24,473 & 1.9 & 0.00072 \\
RNY4P1 & 68 & 146 & 2.1 & 0.00090 \\
RNY4P25 & 180 & 317 & 1.7 & 0.0032 \\
\hline
\end{tabular}




\section{a}
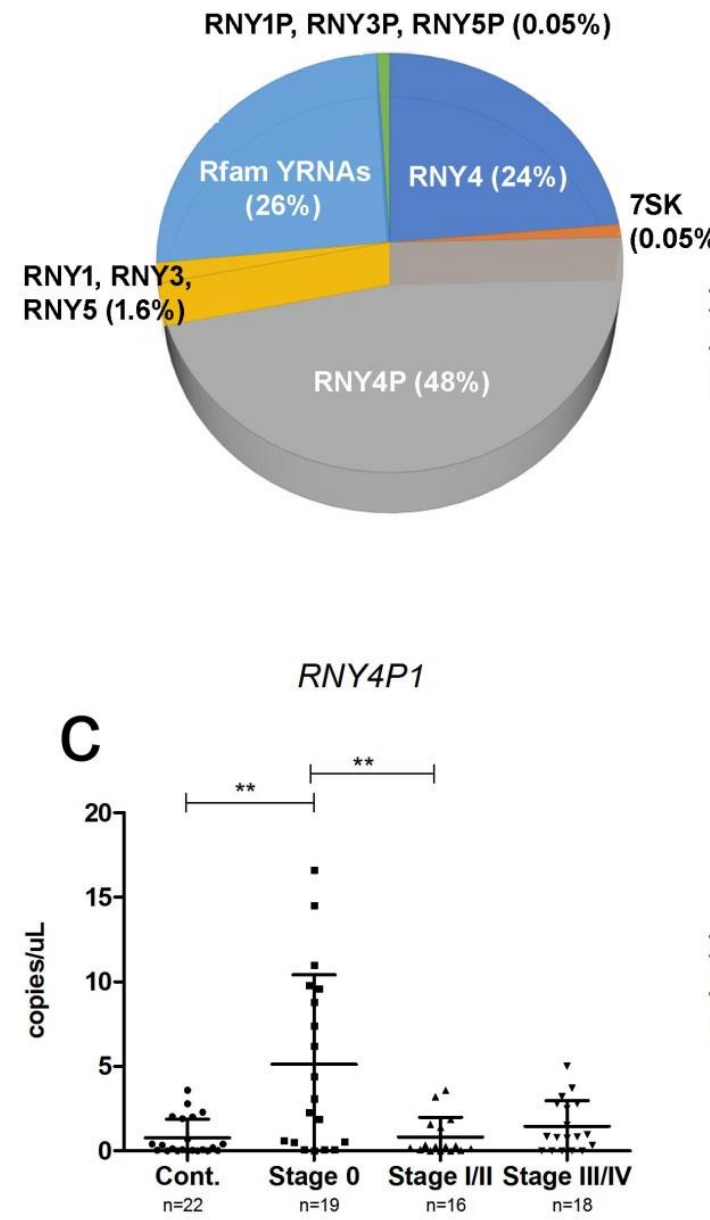

b

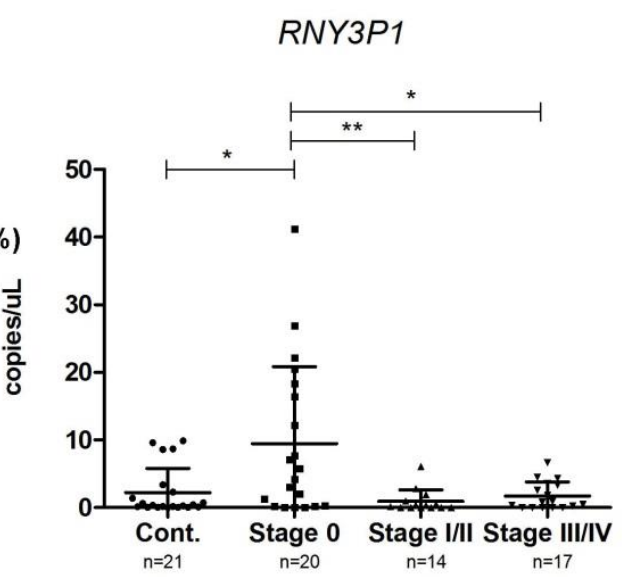

RNY4P25

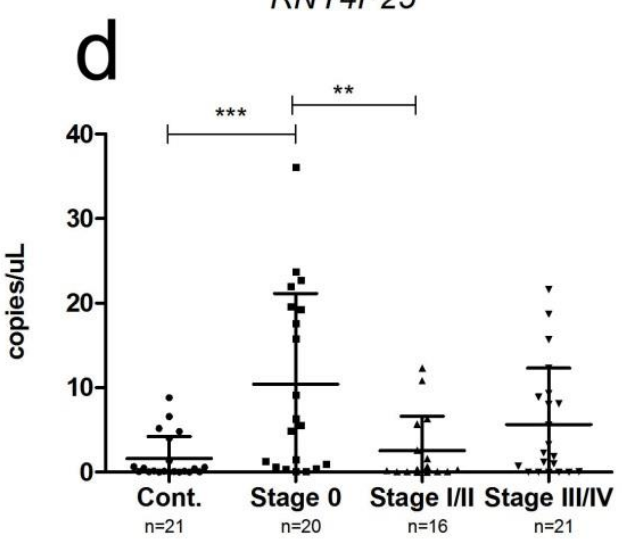

Figure 4. YRNA expression in plasma samples. (a) Mean proportions of different YRNA species in NGS cohort plasma samples. Levels of (b) RNY3P1, (c) RNY4P1 and (d) RNY4P25 measured by ddPCR in an independent validation cohort of 80 plasma samples (22 controls and 58 melanoma patients). Values are shown as absolute copies per $\mu$ l. Expression levels were compared using the Kruskal-Wallis multiple comparison test (all the YRNA fragments had $p$-values of $<0.001$ ), and the Mann-Whitney independent $t$-test to carry out a pairwise comparison between groups, $\left({ }^{*} p<0.5 ;{ }^{* *} p<0.01^{* * *} p<0.001\right)$.

\section{Discussion}

The presence and relative stability of cfRNA in biological fluids has led to a great deal of interest in their use as 'liquid biopsies' for disease, in particular for cancer. However, with the exception of miRNAs, the circulating transcriptome remains largely unexplored. While NGS offers researchers the ability to elucidate the circulating transcriptome in its entirety, and therefore to identify novel biomarkers of disease, the application of RNAseq to biofluids such as plasma poses many challenges, not least the low quantity and quality of RNA present in these samples. As a consequence, studies to date have focused on the technical optimization of these techniques [19-21]. However, very few studies to date have sought to assess the potential usefulness of their findings through validation in independent cohorts.

In order to fully explore the complexity and biomarker potential of the melanoma circulating transcriptome, we pooled samples to maximize the starting quantity of cfRNA. As a result, we were able to obtain 40-50 million reads per pooled sample, an order of magnitude higher than comparable studies [20,22]. In contrast to exosomal cfRNA [22], we found that miRNAs only represented a minor 
component $(<3 \%)$ of the whole plasma circulating transcriptome, levels similar to other plasma NGS studies [19-21]. We identified 442 different miRNAs in our samples, somewhat higher than that reported in comparable studies $[23,24]$, probably as a result of the pooled design and the higher quantity of RNA that we used. Consistent with other studies, we found that let-7b, miR-423, and miR-320a-3p were the most highly expressed miRNAs in our plasma samples [20]. We identified eleven miRNAs that were differentially expressed between healthy controls and the different clinical stages of melanoma (Table 2). This included miR-21, which has previously been shown to be upregulated in melanoma plasma samples [25], and $m i R-92 b$ and $m i R-628$, both of which are more highly expressed in plasma from monosomy 3 uveal melanoma patients [26].

Based on our sequencing results, we measured the expression of $m i R-320 a-3 p$ and miR-134-5p, the two miRNAs most differentially expressed between samples, in a validation cohort of 96 melanoma patients and 28 controls. Both miRNAs were significantly down-regulated $(p<0.0001)$ in plasma from all stages of melanoma patients when compared to samples from healthy controls. MiR-320a has also been found to be down-regulated in melanoma tumor cells when compared to heathy skin samples [27]. Furthermore, this miRNA was shown to function as an inhibitor of cell proliferation. The down-regulation of miR-320a has been observed in the blood of several cancers including colorectal cancer [28], gastric cancer [29], and retinoblastoma [30]. Moreover, miR-320a is up-regulated in melanoma cells after treatment with bevacizumab or rapamycin + bevacizumab [31]. Furthermore, miR-134 has been characterized as a tumor suppressor, acting to regulate proliferation, apoptosis, and invasion and migration in a wide range of cancer types, including melanoma [32,33]. ROC analysis of miRNA expression gave AUC values of 0.798 and 0.788 respectively. The miR-320a miRNA had a sensitivity of $90 \%$, whereas $m i R-134$ had a specificity of $96 \%$, suggesting these two miRNAs in combination could be useful biomarkers for melanoma.

Even though circulating extracellular mRNA was first detected in 1999 (in melanoma) [34], as the vast majority of circulating mRNA is degraded by blood RNase activity [35], this potential source of biomarkers has largely been overlooked, even though mRNA fragments can represent up to $75 \%$ of total cfRNA [19]. In our study, just over $5 \%$ of mapped reads corresponded to protein-encoding mRNA fragments. We detected 3672 probes ( $<500$ bases in length) that had at least 25 mapped reads in our samples. Nearly $40 \%$ of the probes mRNA fragments mapped to the $5^{\prime}$-terminus (i.e., first $10 \%$ ) of their respective gene transcripts, probably reflecting the $3^{\prime}$ to $5^{\prime}$ cleavage activity of RNase A, the major RNase species in blood [26]. We did not notice a corresponding shift in the length profile between healthy and melanoma patient samples [36].

Pathway analysis of the genes corresponding to differentially-expressed mRNA fragments showed significant enrichment in the angiopoietin, p21-activated kinase (PAK) and Eukaryotic Initiation Factor 2 (EIF2) pathways. It has been previously reported that circulating level of Angiopoietin-2 (Ang-2) protein in melanoma patient sera closely correlates with disease progression [37]. Similarly, amplification of the PAK (p21-activated kinase) pathway is characteristic of BRAF-wild type melanoma [38], while in BRAF-mutant melanoma it is responsible for resistance to MAPK-inhibitor treatment [39]. Interestingly, both SOS1 and ATM1, which were the third and fourth most differentially expressed probe sets in our analysis, form part of the angiopoietin, PAK, and EIF2 pathways. We measured levels of SOS1, ATM1, CD109, and AMFR mRNA fragments in plasma samples from 173 melanoma patients and 47 healthy controls. With the exception of CD109, these mRNA fragments mapped to regions corresponding to the $5^{\prime}$-terminus of the reference gene transcript and included the initiation codon. Consistent with the NGS data (Table A1), levels of all these mRNA fragments were up-regulated in melanoma patient samples compared to samples from healthy controls. Particularly intriguing was the up-regulation of CD109 and AMFR in stage 0 samples compared to samples from more advanced stage melanoma, suggesting that these mRNA fragments could be used for early diagnosis of melanoma, although we do not have data on how many of these patients went on to develop advanced disease. (Figure 3b-e). CD109 has been identified as an important regulator of the Epithelial-mesenchymal transition (EMT pathway), and has also been 
found to be down-regulated in more advanced stage hepatocellular carcinoma [40]. The product of the $A M F R$ gene, gp78, also regulates EMT, and increasing levels of AMFR are associated with metastatic melanoma [41,42]. Intriguingly, CD109 is a predicted target of $m i R-134$ by the Targetscan algorithm; we are currently carrying out experiments to confirm this. ATM1 is a serine/threonine kinase induced by DNA damage and associated with risk in many cancer types [43]. SOS1 is a guanine nucleotide exchange factor for RAS proteins frequently mutated in melanoma [44]. Interestingly, all four of these gene fragments were more highly expressed not only in advanced stage disease, but also stage 0 disease; indeed, levels of $C D 109$ and $A M F R$ were higher in plasma from stage 0 disease than more advanced stage disease, suggesting that these biomarkers maybe non-tumoral in origin. Consistent with this hypothesis, the release of $C D 109$ by bone marrow mesenchymal stem cells has recently been shown to attenuate EMT in skin squamous cell carcinoma [45], and AMFR plays an important role in regulation of the anti-cancer immune Stimulator of interferon genes (STING) pathway [46].

To test the potential diagnostic ability of these biomarkers, we carried out ROC analysis, however the results from individual mRNA fragments were poor (AUC range 0.722 (SOS1) to 0.767 (ATM1). In contrast, a combination of ATM1, SOS1, and AMFR resulted in an AUC value of 0.825 with a sensitivity of $75 \%$ and specificity of $92 \%$. Although these findings need to be confirmed independently, this combination compares very favorably with existing sera markers such as LDH and S100B with reported sensitivities/specificities of $41.6 / 84.2 \%$ and $36.3 / 96.5 \%$, respectively [47].

By far the largest class of circulating cfRNA that we identified in the samples corresponded to YRNA sequences, accounting for close to $50 \%$ of sRNA mapped reads. Remarkably, despite the prevalence of cfYRNAs in the blood, there is very little known about this class of ncRNA. YRNAs are short 80-110 nt ncRNAs, first identified in the early 1980s as an RNA component of the soluble Ro60 ribonucleoprotein particle found in the blood of patients with autoimmune diseases [48]. The function of YRNAs is still poorly understood; they appear to be essential for DNA replication [49] and are up-regulated in cancers [50], presumably as a result of their association with apoptosis [51]. The first description of circulating cfYRNAs came in 2013 from Dhahbi et al., who observed that 33\% of mapped reads from sera of healthy individuals were YRNA sequences [52]. The same group later reported that YRNA accounts for 38\% of cfRNA in sera from breast cancer patients [53], and subsequently, in the sera of head and neck squamous cell carcinoma patients [54]. More recently, a study of 183 plasma samples from healthy individuals found that YRNAs accounted for $63 \%$ of cfRNA [55]. As far as we are aware, apart from a recent study that measured YRNAs in the sera of 30 renal carcinoma patients [56], this the first study to look at the biomarker potential of YRNAs in cancer patients. Interestingly, we found that levels of YRNAs were significantly higher in samples from patients with stage 0 disease, maybe pointing to increased levels of tumor-associated apoptosis [51] even despite the small tumor sizes compared to more advanced disease stages.

In summary, we have elucidated the circulating transcriptome of plasma samples from melanoma patients and found a number of novel RNA biomarker species that we validated independently using qRT-PCR and ddRT-PCR in combined retrospective and prospective cohorts, detected from only $1 \mathrm{~mL}$ of serum. These findings have potential clinical utility as new tools for early detection of melanoma, particularly as our results suggest that these biomarkers can detect disease much earlier than current diagnostic techniques. Furthermore, as blood-based biomarkers, there is potential for screening of non-symptomatic individuals. Whilst it is clear that much further validation is required, this study provides strong evidence that the circulating transcriptome holds much promise as a source of liquid biopsies for melanoma that surely merits further exploration.

\section{Materials and Methods}

\subsection{Patient Cohorts}

Patient plasma samples were collected both retrospectively $(n=119)$ and prospectively $(n=289)$. Retrospective samples were obtained from the John Radcliffe Hospital, Oxford (Oxford cohort; $n=30$ ), 
and the AVAST-M multi-center phase 3 clinical trial (AVAST-M cohort; $n=89$ ) [57]. Samples collected prospectively came either from the Hospital 12 de Octubre in Madrid (Madrid cohort; $n=67$ ) or the Onkologikoa Cancer Hospital and Donostia University Hospital of San Sebastián (San Sebastián cohort; $n=102$ ): a total of 327 melanoma patients (Table 5). The clinical details of the individual patients included in these cohorts are given in Supplementary Tables S4-S7. Samples were collected at the time of diagnosis and prior to any treatment. Unfortunately, no information was available regarding the sequence of $C D K N 2 A$. Plasma samples from age/sex matched healthy controls $(n=99)$ were obtained from the Basque Biobank for Research O+EHUN. Plasma preparation was carried out within $1 \mathrm{~h}$ of phlebotomy, with blood collected in EDTA-coated tubes followed by centrifugation for $1000 \times g$ for 15 min at $4{ }^{\circ} \mathrm{C}$.

Table 5. Details of origin of patient cohorts used in study.

\begin{tabular}{ccc}
\hline & Cohort & n Samples \\
\hline \multirow{3}{*}{ mRNA } & Oxford & 30 \\
& AVAST-M & 83 \\
& Madrid & 51 \\
& San Sebastián & 67 \\
\multirow{2}{*}{ miRNA } & AVAST-M & 6 \\
& Madrid & 35 \\
& San Sebastián & 83 \\
\hline \multirow{2}{*}{ yRNA } & Madrid & 51 \\
& San Sebastián & 67 \\
\hline
\end{tabular}

With the exception of the 37 prospectively collected samples used for NGS (Table 1), only a limited volume (1-2 mL) of plasma was available for validation studies. Therefore, we divided samples into three separate validation cohorts; a miRNA cohort of 96 melanoma patients and 28 controls; an mRNA cohort of 173 melanoma patients and 47 controls; and a YRNA cohort of 58 melanoma patients and 22 controls. The clinical details of the patients used are summarized in Table 1, and details of individual cohorts are provided in Table 4 and Supplementary Tables S4-S7. Written informed consent was obtained from patients for the inclusion of their samples in this study, and samples were collected in accordance with the Declaration of Helsinki and approved by local ethics committees (CEIC-Euskadi approval number PI2015024).

For the plasma samples used for NGS (5-8 mL), cfRNA was purified using the plasma RNA purification kit from Norgen Biotek (Ontario, Canada), and for validation studies ( $1 \mathrm{~mL}$ samples) the miRCURYTM RNA Isolation Kit Biofluids from Exiqon (Vedbaek, Denmark) was used.

\subsection{Library Construction and Next-Generation Sequencing}

The samples used for NGS were pooled according to disease stage, as shown in Table 1. Ribosomal RNA (rRNA) was removed from total cfRNA using the Ribozero Magnetic Human/Mouse/Rat kit (Epicentre (Maidon, WI, USA), \#MRZH116), according to the low input protocol recommended by the manufacturer. Phosphatase and T4 polynucleotide kinase (PNK) treatments were carried out on the ribo-depleted RNA, and Illumina small RNA adapters ligated. Libraries were amplified using 15 cycles of PCR of barcoded primers [58]. Sequencing was performed on an Illumina HiSeq 2500 as $50 \mathrm{PE}$ in rapid mode.

\subsection{Bioinformatic Analysis}

Sequencing reads were quality filtered using the fastx_artifacts_filter tool, and ligation adapters were removed using the AdRec.jar program (seqBuster suite of programs (omicX (Le-Petit-Quevilly, Le Petit-Quevilly, France))). Reads were mapped to the GRCh37 build of the human genome using the Bowtie 2.0 algorithm. A custom annotated probe set was built by combining probes from GENCODE 
version 8 [59], supplemented with rRNA and repeat annotations from RepeatMasker GRCh37, and snoRNA annotations from the UCSC table browser [60]. Expression of miRNA was calculated using the miraligner algorithm from the seqBuster suite, and YRNA expression was calculated using the HTseq-count algorithm. Differential expression analysis was carried out using the DESeq bioconductor package [61].

\section{4. $q R T-P C R$ ( $m R N A$ and $m i R N A)$ and $d d P C R(y R N A s)$}

mRNA was reverse transcribed (RT) using random primers with the High Capacity cDNA Reverse Transcription Kit from Applied Biosystems following the manufacturers' protocol with DNase treatment. Due to the difficulty in quantifying cfRNA reliably, we used fixed volumes in reactions $[4,62]$. For gene fragments, we designed custom Taqman probes using the Custom TaqMan ${ }^{\circledR}$ Assay Design Tool from Applied Biosystems (Foster City, CA, USA), using the sequences corresponding to the respective probe sets (Supplementary Table S2 and Figure S1). The reference gene used for mRNA analysis was $18 \mathrm{~S}$ rRNA, as previously described [63].

For miRNA detection, we used the Megaplex RT Primers Human Pool A v2.1 for RT, and specific Taqman probes as described in the text. As the problems of defining suitable reference genes for miRNA detection in plasma are well documented [4], we measured levels of three previously described reference miRNAs (miR-24, miR-16 and miR-191) [64,65], in a cohort of 63 samples (control/stage $0(n=22)$, stage I/II $(n=26)$, stage III/IV $(n=15))$. Using the NormFinder algorithm we identified miR-24 and miR-191 as the most stable combination of reference genes in our samples (Supplementary Figure S3).

Custom primers and Taqman probes for Y3P1, Y4P1 and Y4P25 were designed using the Custom Taqman ${ }^{\circledR}$ Small RNA Assay Design Tool from Applied Biosystems. We performed ddPCR using QX200TM Droplet DigitalTM PCR system (Bio Rad, Hercules CA, USA), following the manufacturers' protocol. Data analysis was performed by QuantaSoft analysis software from Bio-Rad. Expression levels were compared using the Kruskal-Wallis multiple comparison test, and the Mann-Whitney independent t-test to carry out a pairwise comparison between individual groups (Graphpad Prism v. 5.0, La Jolla, CA, USA). ROC analysis and comparisons were carried out using the method of DeLong et al., as implemented in MedCalc v. 14.8 software [66].

\section{Conclusions}

We have carried out a comprehensive, non-biased elucidation of the circulating transcriptome of melanoma patients and identified a number of promising candidate biomarker RNA species, not only miRNAs. These candidates were validated in independent cohorts by ourselves, however it is clear that further studies should be carried out by independent research groups in order to strengthen our findings and facilitate the translation of this knowledge into the clinic.

What is obvious is that many virtually unexplored classes of the circulating transcriptome are yet to be fully assessed for their ability to serve as useful cancer biomarkers. As a consequence, while the discovery of circulating miRNAs represented an important event in the history of the liquid biopsy field, it is clear that there is much that we have still to explore.

Supplementary Materials: The following are available online at http:/ /www.mdpi.com/2072-6694/11/1/70/s1, Figure S1: Mapping positions (GRCh37) of selected gene fragment probe sets used to design Taqman probes. Figure S2: Variation of Ct values in levels of miRNA reference genes in selected cohort measured by qRT-PCR. Figure S3: ROC analysis of mRNA expression in different melanoma stage cohorts. Table S1: Summary of NGS results from pooled RNA samples. Table S2: Characteristics of selected differentially protein-encoding gene fragment probe sets. Table S3: YRNA reads from NGS. Table S4: Clinical details of patients used for NGS cohort. Table S5: Clinical details of patients used in mRNA validation cohort. Table S6: Clinical details of patients used in miRNA validation cohort. Table S7: Clinical details of patients used in yRNA validation cohort.

Author Contributions: conceptualization, C.S.; D.T. and C.H.L.; methodology, C.S., M.S., I.G., M.T. and C.H.L; validation, C.S., M.A., L.I.H., L.M., M.S.; formal analysis, M.R.F., M.F.-M., P.P., X.E., I.G., M.T. and C.H.L; resources, D.T., K.M., A.T., A.J., P.L.O.-R., M.R.M.; data curation, P.L.O.-R., M.T., M.R.M.; writing-original draft preparation, C.S. and C.H.L.; writing-review and editing, C.S. and C.H.L. 
Funding: C.H.L. and his research is supported by grants from the IKERBASQUE foundation for science, the Starmer-Smith memorial fund, Ministerio de Economía y Competitividad (MINECO) of the Spanish Central Government and FEDER funds (PI12/00663, PIE13/00048, DTS14/00109, PI15/00275), Departamento de Desarrollo Económico y Competitividad y Departamento de Sanidad of the Basque government, Asociación Española Contra el Cancer (AECC), and the Diputación Foral de Guipuzcoa (DFG). M.R.F. was supported by EMBO Long-Term fellowship ALTF 225-2011. M.F.-M also acknowledges support from MINECO (PI16/00159), DFG and AECC.

Acknowledgments: We thank the Basque Biobank for Research O+EHUN for the plasma samples.

Conflicts of Interest: The authors declare no conflict of interest.

\section{Appendix A}

Table A1. Differentially expressed protein-encoding probe sets $(p<0.05)$. Gene names and coordinates are given. Counts were normalized per million reads. mRNAs validated are depicted in bold.

\begin{tabular}{|c|c|c|c|c|c|c|c|c|}
\hline Gene & Chromosome Position & Length & $p$-Value & Cont. & St. 0 & St. I/II & St. III & St. IV \\
\hline CD109 & 6:74446106-74446231 & 125 & 0.00103 & 39 & 102 & 126 & 207 & 318 \\
\hline ARHGAP & 4:148744047-148744108 & 61 & 0.0018 & 45 & 9 & 11 & 10 & 8 \\
\hline SOS1 & 2:39237725-39237844 & 119 & 0.00196 & 23 & 16 & 130 & 121 & 139 \\
\hline ATM & 11:108099905-108100050 & 145 & 0.00316 & 5 & 20 & 8 & 7 & 105 \\
\hline$A M F R$ & 16:56396751-56396855 & 104 & 0.00329 & 11 & 32 & 59 & 59 & 121 \\
\hline KCNIP3 & 2:95976103-95976544 & 441 & 0.00362 & 1 & 14 & 22 & 16 & 28 \\
\hline POLE & 12:133248801-133248908 & 107 & 0.00456 & 0 & 36 & 11 & 12 & 72 \\
\hline KLHL7 & $7: 23213634-23214040$ & 406 & 0.00479 & 0 & 6 & 10 & 8 & 40 \\
\hline ZMYM4 & 1:35824626-35825047 & 421 & 0.00547 & 54 & 23 & 25 & 27 & 22 \\
\hline GTDC1 & 2:144966170-144966371 & 211 & 0.00632 & 58 & 15 & 16 & 21 & 14 \\
\hline RFWD2 & 1:176132951-176133027 & 76 & 0.00651 & 27 & 11 & 10 & 13 & 12 \\
\hline ARHGAP10 & 4:148778704-148779039 & 335 & 0.00672 & 31 & 10 & 13 & 11 & 13 \\
\hline RHBDD1 & 2:227778924-227779353 & 429 & 0.00774 & 71 & 63 & 39 & 33 & 28 \\
\hline HNRNPM & 19:8527413-8527473 & 60 & 0.00798 & 42 & 15 & 20 & 17 & 19 \\
\hline DYNC2H1 & 11:102988360-102988592 & 232 & 0.00835 & 0 & 15 & 17 & 15 & 60 \\
\hline ITIH5 & 10:7613668-7614061 & 393 & 0.00885 & 0 & 11 & 12 & 6 & 32 \\
\hline TNFA1P2 & 14:103592664-103593029 & 365 & 0.00974 & 29 & 28 & 84 & 76 & 60 \\
\hline SLC40A1 & 2:190430080-190430325 & 245 & 0.00996 & 21 & 20 & 31 & 28 & 34 \\
\hline SETDB1 & 1:150902443-150902932 & 489 & 0.0106 & 1 & 20 & 23 & 17 & 60 \\
\hline$I G F 2 B P 3$ & 7: 23385559-23385780 & 221 & 0.0118 & 27 & 27 & 11 & 14 & 15 \\
\hline DENND3 & 8:142152302-142153707 & 205 & 0.0118 & 0 & 13 & 32 & 4 & 3 \\
\hline GAK & 4:866054-866461 & 407 & 0.014 & 0 & 11 & 16 & 10 & 40 \\
\hline ARHGEF12 & 11: 120278447-120282546 & 99 & 0.015 & 72 & 78 & 52 & 39 & 44 \\
\hline HINT3 & $6: 126298790-126301387$ & 497 & 0.0157 & 76 & 66 & 8 & 19 & 11 \\
\hline HTR1E & 6: 87647124-87647541 & 417 & 0.0158 & 41 & 95 & 106 & 75 & 92 \\
\hline UXS1 & 2:106780123-106780166 & 43 & 0.0171 & 60 & 5 & 5 & 6 & 2 \\
\hline$M P P 2$ & 17: 41983448-41983519 & 71 & 0.0173 & 11 & 9 & 22 & 29 & 18 \\
\hline NAIP & 5: 70308275-70308745 & 470 & 0.0183 & 0 & 10 & 41 & 5 & 2 \\
\hline SNCA & 4:90757894-90758379 & 485 & 0.0185 & 73 & 44 & 49 & 49 & 41 \\
\hline TRAPPC9 & 8:140922366-140922544 & 178 & 0.0185 & 28 & 68 & 76 & 53 & 59 \\
\hline PISD & 22:32034352-32034488 & 136 & 0.0189 & 225 & 533 & 600 & 413 & 557 \\
\hline SERPINB1 & 6: 2836090-2836257 & 233 & 0.0193 & 29 & 14 & 10 & 14 & 13 \\
\hline GRN & $17: 42429383-42429616$ & 167 & 0.0193 & 0 & 7 & 25 & 2 & 2 \\
\hline EIF4G3 & 1: 21231376-21231464 & 88 & 0.0195 & 49 & 45 & 38 & 33 & 33 \\
\hline$I L K$ & 11: $6624961-6625456$ & 495 & 0.0196 & 28 & 49 & 46 & 59 & 47 \\
\hline C14ORF38 & 14:60031765-60031993 & 240 & 0.0197 & 26 & 7 & 11 & 9 & 7 \\
\hline PSAP & $10: 73578788-73579028$ & 228 & 0.0197 & 1 & 13 & 27 & 44 & 13 \\
\hline TMEM104 & 17: 72835466-72835918 & 452 & 0.0212 & 46 & 35 & 11 & 19 & 16 \\
\hline TAOK1 & 17:27849298-27849537 & 239 & 0.0217 & 42 & 9 & 12 & 6 & 11 \\
\hline SIAE & 11: 124506788-124507098 & 310 & 0.022 & 26 & 22 & 6 & 12 & 7 \\
\hline CDK5RAP2 & 9: $123165584-123165940$ & 356 & 0.0229 & 4347 & 9583 & 12031 & 8114 & 9164 \\
\hline TPT1 & 13: 45911208-45911614 & 406 & 0.0239 & 55 & 31 & 38 & 34 & 30 \\
\hline SSH3 & 11:67070919-67071162 & 243 & 0.024 & 236 & 73 & 71 & 46 & 40 \\
\hline$S S B$ & 2:170667368-170667554 & 186 & 0.0247 & 0 & 8 & 28 & 7 & 1 \\
\hline
\end{tabular}


Table A1. Cont.

\begin{tabular}{ccccccccc}
\hline Gene & Chromosome Position & Length & $p$-Value & Cont. & St. 0 & St. I/II & St. III & St. IV \\
\hline ZNF430 & $19: 21216892-21216990$ & 98 & 0.025 & 48 & 11 & 17 & 12 & 8 \\
HBA2 & $16: 222846-223262$ & 494 & 0.0266 & 266 & 141 & 135 & 177 & 134 \\
ZFPM2 & $8: 106456508-106456609$ & 101 & 0.0304 & 70 & 41 & 43 & 49 & 49 \\
RBM5 & $3: 50145665-50145738$ & 73 & 0.0308 & 60 & 19 & 16 & 28 & 16 \\
ITGB1 & $10: 33218750-33218972$ & 222 & 0.0312 & 80 & 37 & 29 & 45 & 32 \\
ZCCHC17 & $1: 31821676-31821821$ & 145 & 0.0329 & 15 & 17 & 20 & 23 & 26 \\
PRKG2 & $4: 82136085-82136218$ & 133 & 0.0332 & 40 & 49 & 20 & 29 & 26 \\
IFI6 & $1: 27992572-27992986$ & 414 & 0.0341 & 0 & 0 & 46 & 1 & 2 \\
MX2 & $21: 42774561-42776800$ & 458 & 0.0363 & 0 & 0 & 31 & 1 & 1 \\
PSMD2 & $3: 184020467-184020611$ & 144 & 0.0366 & 0 & 2 & 12 & 28 & 1 \\
HERC6 & $4: 89363186-89364063$ & 477 & 0.0376 & 0 & 3 & 54 & 4 & 1 \\
PPBP & $4: 74853673-74853914$ & 241 & 0.0387 & 685 & 259 & 301 & 403 & 260 \\
PKN2 & $1: 89206671-89206971$ & 300 & 0.0389 & 66 & 27 & 27 & 22 & 15 \\
TNIP1 & $5: 150415143-150415268$ & 125 & 0.039 & 7 & 5 & 36 & 16 & 14 \\
ARGLU1 & $13: 107209096-107210043$ & 347 & 0.0396 & 0 & 11 & 42 & 5 & 6 \\
LRRN2 & $1: 204654448-204654861$ & 413 & 0.0399 & 13 & 43 & 29 & 25 & 32 \\
ACACB & $12: 109625804-109625967$ & 163 & 0.0401 & 19 & 46 & 43 & 30 & 40 \\
EIF5B & $2: 99980108-99980325$ & 217 & 0.0415 & 39 & 14 & 22 & 18 & 15 \\
FRA10AC1 & $10: 95441237-95441355$ & 118 & 0.0419 & 33 & 6 & 6 & 5 & 2 \\
RASA1 & $5: 86627165-86627317$ & 152 & 0.0437 & 35 & 10 & 15 & 17 & 16 \\
CHD9 & $16: 53301839-53302038$ & 199 & 0.0441 & 41 & 10 & 11 & 20 & 13 \\
TPM1 & $15: 63351762-63351879$ & 117 & 0.0443 & 38 & 12 & 18 & 19 & 12 \\
ACVR2 & $2: 148657313-148657467$ & 154 & 0.0462 & 26 & 21 & 16 & 10 & 14 \\
MCTP1 & $5: 94224580-94224677$ & 250 & 0.0475 & 6 & 12 & 20 & 19 & 25 \\
HOXC6 & $12: 54404873-54407570$ & 97 & 0.0481 & 26 & 62 & 71 & 45 & 49 \\
ATF4 & $22: 39916183-39917676$ & 267 & 0.0487 & 26 & 28 & 18 & 18 & 18 \\
\hline
\end{tabular}

\section{References}

1. Siegel, R.L.; Miller, K.D.; Jemal, A. Cancer Statistics, 2017. CA Cancer J. Clin. 2017, 67, 7-30. [CrossRef] [PubMed]

2. Weinstock, M.A. Epidemiology, etiology, and control of melanoma. Med. Health R. I. 2001, 84, $234-236$. [PubMed]

3. Forsea, A.M.; Del Marmol, V.; de Vries, E.; Bailey, E.E.; Geller, A.C. Melanoma incidence and mortality in Europe: New estimates, persistent disparities. Br. J. Dermatol. 2012, 167, 1124-1130. [CrossRef] [PubMed]

4. Fernandez-Mercado, M.; Manterola, L.; Larrea, E.; Goicoechea, I.; Arestin, M.; Armesto, M.; Otaegui, D.; Lawrie, C.H. The circulating transcriptome as a source of non-invasive cancer biomarkers: Concepts and controversies of non-coding and coding RNA in body fluids. J. Cell. Mol. Med. 2015, 19, 2307-2323. [CrossRef] [PubMed]

5. Lawrie, C.H.; Gal, S.; Dunlop, H.M.; Pushkaran, B.; Liggins, A.P.; Pulford, K.; Banham, A.H.; Pezzella, F.; Boultwood, J.; Wainscoat, J.S.; et al. Detection of elevated levels of tumour-associated microRNAs in serum of patients with diffuse large B-cell lymphoma. Br. J. Haematol. 2008, 141, 672-675. [CrossRef] [PubMed]

6. Shiiyama, R.; Fukushima, S.; Jinnin, M.; Yamashita, J.; Miyashita, A.; Nakahara, S.; Kogi, A.; Aoi, J.; Masuguchi, S.; Inoue, Y.; et al. Sensitive detection of melanoma metastasis using circulating microRNA expression profiles. Melanoma Res. 2013, 23, 366-372. [CrossRef] [PubMed]

7. Friedman, E.B.; Shang, S.; de Miera, E.V.; Fog, J.U.; Teilum, M.W.; Ma, M.W.; Berman, R.S.; Shapiro, R.L.; Pavlick, A.C.; Hernando, E.; et al. Serum microRNAs as biomarkers for recurrence in melanoma. J. Transl. Med. 2012, 10, 155. [CrossRef] [PubMed]

8. Savelyeva, A.V.; Kuligina, E.V.; Bariakin, D.N.; Kozlov, V.V.; Ryabchikova, E.I.; Richter, V.A.; Semenov, D.V. Variety of RNAs in Peripheral Blood Cells, Plasma, and Plasma Fractions. Biomed. Res. Int. 2017, 2017, 7404912. [CrossRef]

9. Wong, B.C.; Lo, Y.M. Plasma RNA integrity analysis: Methodology and validation. Ann. N. Y. Acad. Sci. 2006, 1075, 174-178. [CrossRef]

10. Pruijn, G.J.; Wingens, P.A.; Peters, S.L.; Thijssen, J.P.; van Venrooij, W.J. Ro RNP associated Y RNAs are highly conserved among mammals. Biochim. Biophys. Acta 1993, 1216, 395-401. [CrossRef] 
11. Stein, A.J.; Fuchs, G.; Fu, C.; Wolin, S.L.; Reinisch, K.M. Structural insights into RNA quality control: The Ro autoantigen binds misfolded RNAs via its central cavity. Cell 2005, 121, 529-539. [CrossRef]

12. Christov, C.P.; Gardiner, T.J.; Szuts, D.; Krude, T. Functional requirement of noncoding Y RNAs for human chromosomal DNA replication. Mol. Cell. Biol. 2006, 26, 6993-7004. [CrossRef]

13. Sim, S.; Wolin, S.L. Emerging roles for the Ro $60-\mathrm{kDa}$ autoantigen in noncoding RNA metabolism. Wiley Interdiscip. Rev. RNA 2011, 2, 686-699. [CrossRef]

14. Sole, C.; Tramonti, D.; Schramm, M.; Goicoechea, I.; Armesto, M.; Hernandez, L.I.; Manterola, L.; Fernandez-Mercado, M.; Mujika, K.; Tuneu, A.; Jaka, A.; et al. Biodonostia Research Institute; University of Oxford; University of Heidelberg; Oncology Institute of Gipuzkoa; Hospital Universitario Donostia; Centre for Genomic Regulation; Universitat Pompeu Fabra; CIBERESP; Hospital del Mar Research Institute; Stockholm University; Imperial College London; de Octubre Hospital; CIBERONC; IKERBASQUE. (Library optimization for sequencing of circulating transcriptome in melanoma patients) San Sebastian, Spain, unpublished work, 2018.

15. Fuchs, R.T.; Sun, Z.; Zhuang, F.; Robb, G.B. Bias in ligation-based small RNA sequencing library construction is determined by adaptor and RNA structure. PLoS ONE 2015, 10, e0126049. [CrossRef]

16. Sole, C.; Tramonti, D.; Schramm, M.; Goicoechea, I.; Armesto, M.; Hernandez, L.I.; Manterola, L.; Fernandez-Mercado, M.; Mujika, K.; Tuneu, A.; et al. Biodonostia Research Institute; University of Oxford; University of Heidelberg; Oncology Institute of Gipuzkoa; Hospital Universitario Donostia; Centre for Genomic Regulation; Universitat Pompeu Fabra; CIBERESP; Hospital del Mar Research Institute; Stockholm University; Imperial College London; de Octubre Hospital; CIBERONC; IKERBASQUE. miR-21-5p and miR-92b-3p detection in Melanoma. San Sebastian, Spain, unpublished work, 2018.

17. Sole, C.; Tramonti, D.; Schramm, M.; Goicoechea, I.; Armesto, M.; Hernandez, L.I.; Manterola, L.; Fernandez-Mercado, M.; Mujika, K.; Tuneu, A.; et al. Biodonostia Research Institute; University of Oxford; University of Heidelberg; Oncology Institute of Gipuzkoa; Hospital Universitario Donostia; Centre for Genomic Regulation; Universitat Pompeu Fabra; CIBERESP; Hospital del Mar Research Institute; Stockholm University; Imperial College London; de Octubre Hospital; CIBERONC; IKERBASQUE. mRNA targets of miR-134-5p and miR-320a using predictive algorithms TargetScan and miRDB. San Sebastian, Spain, unpublished work, 2018.

18. Robin, X.; Turck, N.; Hainard, A.; Tiberti, N.; Lisacek, F.; Sanchez, J.C.; Müller, M. PanelomiX: A threshold-based algorithm to create panels of biomarkers. Transl. Proteom. 2013, 1, 57-64. [CrossRef]

19. Qin, Y.; Yao, J.; Wu, D.C.; Nottingham, R.M.; Mohr, S.; Hunicke-Smith, S.; Lambowitz, A.M. High-throughput sequencing of human plasma RNA by using thermostable group II intron reverse transcriptases. RNA 2016, 22, 111-128. [CrossRef]

20. Danielson, K.M.; Rubio, R.; Abderazzaq, F.; Das, S.; Wang, Y.E. High Throughput Sequencing of Extracellular RNA from Human Plasma. PLoS ONE 2017, 12, e0164644. [CrossRef]

21. Guo, Y.; Vickers, K.; Xiong, Y.; Zhao, S.; Sheng, Q.; Zhang, P.; Zhou, W.; Flynn, C.R. Comprehensive evaluation of extracellular small RNA isolation methods from serum in high throughput sequencing. BMC Genom. 2017, 18, 50. [CrossRef] [PubMed]

22. Yuan, T.; Huang, X.; Woodcock, M.; Du, M.; Dittmar, R.; Wang, Y.; Tsai, S.; Kohli, M.; Boardman, L.; Patel, T.; et al. Plasma extracellular RNA profiles in healthy and cancer patients. Sci. Rep. 2016, 6, 19413. [CrossRef] [PubMed]

23. Guo, S.; Guo, W.; Li, S.; Dai, W.; Zhang, N.; Zhao, T.; Wang, H.; Ma, J.; Yi, X.; Ge, R.; et al. Serum miR-16: A Potential Biomarker for Predicting Melanoma Prognosis. J. Investig. Dermatol. 2016, 136, 985-993. [CrossRef]

24. Armand-Labit, V.; Meyer, N.; Casanova, A.; Bonnabau, H.; Platzer, V.; Tournier, E.; Sansas, B.; Verdun, S.; Thouvenot, B.; Hilselberger, B.; et al. Identification of a Circulating MicroRNA Profile as a Biomarker of Metastatic Cutaneous Melanoma. Acta Derm-Venereol. 2016, 96, 29-34. [CrossRef] [PubMed]

25. Saldanha, G.; Potter, L.; Shendge, P.; Osborne, J.; Nicholson, S.; Yii, N.; Varma, S.; Aslam, M.I.; Elshaw, S.; Papadogeorgakis, E.; et al. Plasma microRNA-21 is associated with tumor burden in cutaneous melanoma. J. Investig. Dermatol. 2013, 133, 1381-1384. [CrossRef]

26. Triozzi, P.L.; Achberger, S.; Aldrich, W.; Crabb, J.W.; Saunthararajah, Y.; Singh, A.D. Association of tumor and plasma microRNA expression with tumor monosomy-3 in patients with uveal melanoma. Clin. Epigenet. 2016, 8, 80. [CrossRef] [PubMed] 
27. Kozubek, J.; Ma, Z.; Fleming, E.; Duggan, T.; Wu, R.; Shin, D.G.; Dadras, S.S. In-depth characterization of microRNA transcriptome in melanoma. PLOS ONE 2013, 8, e72699. [CrossRef]

28. Fang, Z.; Tang, J.; Bai, Y.; Lin, H.; You, H.; Jin, H.; Lin, L.; You, P.; Li, J.; Dai, Z.; et al. Plasma levels of microRNA-24, microRNA-320a, and microRNA-423-5p are potential biomarkers for colorectal carcinoma. J. Exp. Clin. Cancer Res. 2015, 34, 86. [CrossRef] [PubMed]

29. Xu, Q.; Dong, Q.G.; Sun, L.P.; He, C.Y.; Yuan, Y. Expression of serum miR-20a-5p, let-7a, and miR-320a and their correlations with pepsinogen in atrophic gastritis and gastric cancer: A case-control study. BMC Clin. Pathol. 2013, 13, 11. [CrossRef] [PubMed]

30. Liu, S.S.; Wang, Y.S.; Sun, Y.F.; Miao, L.X.; Wang, J.; Li, Y.S.; Liu, H.Y.; Liu, Q.L. Plasma microRNA-320, microRNA-let-7e and microRNA-21 as novel potential biomarkers for the detection of retinoblastoma. Biomed. Rep. 2014, 2, 424-428. [CrossRef] [PubMed]

31. Wagenseller, A.G.; Shada, A.; D'Auria, K.M.; Murphy, C.; Sun, D.; Molhoek, K.R.; Papin, J.A.; Dutta, A.; Slingluff, C.L., Jr. MicroRNAs induced in melanoma treated with combination targeted therapy of Temsirolimus and Bevacizumab. J. Transl. Med. 2013, 11, 218. [CrossRef]

32. Pan, J.Y.; Zhang, F.; Sun, C.C.; Li, S.J.; Li, G.; Gong, F.Y.; Bo, T.; He, J.; Hua, R.X.; Hu, W.D.; et al. miR-134: A Human Cancer Suppressor? Mol. Ther. Nucleic Acids 2017, 6, 140-149. [CrossRef]

33. Venkatesan, N.; Kanwar, J.; Deepa, P.R.; Khetan, V.; Crowley, T.M.; Raguraman, R.; Sugneswari, G.; Rishi, P.; Natarajan, V.; Biswas, J.; et al. Clinico-Pathological Association of Delineated miRNAs in Uveal Melanoma with Monosomy 3/Disomy 3 Chromosomal Aberrations. PLoS ONE 2016, 11, e0146128. [CrossRef]

34. Kopreski, M.S.; Benko, F.A.; Kwak, L.W.; Gocke, C.D. Detection of tumor messenger RNA in the serum of patients with malignant melanoma. Clin. Cancer Res. 1999, 5, 1961-1965.

35. Reddi, K.K.; Holland, J.F. Elevated serum ribonuclease in patients with pancreatic cancer. Proc. Natl. Acad. Sci. USA 1976, 73, 2308-2310. [CrossRef]

36. Sole, C.; Tramonti, D.; Schramm, M.; Goicoechea, I.; Armesto, M.; Hernandez, L.I.; Manterola, L.; Fernandez-Mercado, M.; Mujika, K.; Tuneu, A.; et al. Biodonostia Research Institute; University of Oxford; University of Heidelberg; Oncology Institute of Gipuzkoa; Hospital Universitario Donostia; Centre for Genomic Regulation; Universitat Pompeu Fabra; CIBERESP; Hospital del Mar Research Institute; Stockholm University; Imperial College London; de Octubre Hospital; CIBERONC; IKERBASQUE. Length profile in sequencing between healthy and melanoma patient samples. San Sebastian, Spain, unpublished work, 2018.

37. Helfrich, I.; Edler, L.; Sucker, A.; Thomas, M.; Christian, S.; Schadendorf, D.; Augustin, H.G. Angiopoietin-2 levels are associated with disease progression in metastatic malignant melanoma. Clin. Cancer Res. 2009, 15, 1384-1392. [CrossRef] [PubMed]

38. Smalley, K.S.; Weber, J.S. Taming the wild-types: Targeting PAK1 in melanomas that lack BRAF mutations. J. Natl. Cancer Inst. 2013, 105, 591-592. [CrossRef]

39. Lu, H.; Liu, S.; Zhang, G.; Bin, W.; Zhu, Y.; Frederick, D.T.; Hu, Y.; Zhong, W.; Randell, S.; Sadek, N.; et al. PAK signalling drives acquired drug resistance to MAPK inhibitors in BRAF-mutant melanomas. Nature 2017, 550, 133-136. [CrossRef] [PubMed]

40. Emori, M.; Tsukahara, T.; Murase, M.; Kano, M.; Murata, K.; Takahashi, A.; Kubo, T.; Asanuma, H.; Yasuda, K.; Kochin, V.; et al. High expression of CD109 antigen regulates the phenotype of cancer stem-like cells/cancer-initiating cells in the novel epithelioid sarcoma cell line ESX and is related to poor prognosis of soft tissue sarcoma. PLoS ONE 2013, 8, e84187. [CrossRef]

41. Fang, S.; Ferrone, M.; Yang, C.; Jensen, J.P.; Tiwari, S.; Weissman, A.M. The tumor autocrine motility factor receptor, gp78, is a ubiquitin protein ligase implicated in degradation from the endoplasmic reticulum. Proc. Natl. Acad. Sci. USA 2001, 98, 14422-14427. [CrossRef]

42. Timar, J.; Raso, E.; Dome, B.; Ladanyi, A.; Banfalvi, T.; Gilde, K.; Raz, A. Expression and function of the AMF receptor by human melanoma in experimental and clinical systems. Clin. Exp. Metastasis 2002, 19, 225-232. [CrossRef]

43. Russell, R.; Perkhofer, L.; Liebau, S.; Lin, Q.; Lechel, A.; Feld, F.M.; Hessmann, E.; Gaedcke, J.; Guthle, M.; Zenke, M.; et al. Loss of ATM accelerates pancreatic cancer formation and epithelial-mesenchymal transition. Nat. Commun. 2015, 6, 7677. [CrossRef]

44. Halaban, R.; Krauthammer, M. RASopathy Gene Mutations in Melanoma. J. Investig. Dermatol. 2016, 136, 1755-1759. [CrossRef] [PubMed] 
45. Zhou, S.; Cecere, R.; Philip, A. CD109 released from human bone marrow mesenchymal stem cells attenuates TGF-beta-induced epithelial to mesenchymal transition and stemness of squamous cell carcinoma. Oncotarget 2017, 8, 95632-95647. [CrossRef] [PubMed]

46. Wang, Q.; Liu, X.; Cui, Y.; Tang, Y.; Chen, W.; Li, S.; Yu, H.; Pan, Y.; Wang, C. The E3 ubiquitin ligase AMFR and INSIG1 bridge the activation of TBK1 kinase by modifying the adaptor STING. Immunity 2014, 41, 919-933. [CrossRef] [PubMed]

47. Garnier, J.P.; Letellier, S.; Cassinat, B.; Lebbe, C.; Kerob, D.; Baccard, M.; Morel, P.; Basset-Seguin, N.; Dubertret, L.; Bousquet, B.; et al. Clinical value of combined determination of plasma L-DOPA/tyrosine ratio, S100B, MIA and LDH in melanoma. Eur. J. Cancer 2007, 43, 816-821. [CrossRef] [PubMed]

48. Hendrick, J.P.; Wolin, S.L.; Rinke, J.; Lerner, M.R.; Steitz, J.A. Ro small cytoplasmic ribonucleoproteins are a subclass of La ribonucleoproteins: Further characterization of the Ro and La small ribonucleoproteins from uninfected mammalian cells. Mol. Cell. Biol. 1981, 1, 1138-1149. [CrossRef] [PubMed]

49. Zhang, A.T.; Langley, A.R.; Christov, C.P.; Kheir, E.; Shafee, T.; Gardiner, T.J.; Krude, T. Dynamic interaction of $Y$ RNAs with chromatin and initiation proteins during human DNA replication. J. Cell Sci. 2011, 124, 2058-2069. [CrossRef] [PubMed]

50. Christov, C.P.; Trivier, E.; Krude, T. Noncoding human Y RNAs are overexpressed in tumours and required for cell proliferation. Br. J. Cancer 2008, 98, 981-988. [CrossRef] [PubMed]

51. Kowalski, M.P.; Krude, T. Functional roles of non-coding Y RNAs. Int. J. Biochem. Cell Biol. 2015, 66, $20-29$. [CrossRef] [PubMed]

52. Dhahbi, J.M.; Spindler, S.R.; Atamna, H.; Boffelli, D.; Mote, P.; Martin, D.I. 5'-YRNA fragments derived by processing of transcripts from specific YRNA genes and pseudogenes are abundant in human serum and plasma. Physiol. Genom. 2013, 45, 990-998. [CrossRef] [PubMed]

53. Dhahbi, J.M.; Spindler, S.R.; Atamna, H.; Boffelli, D.; Martin, D.I. Deep Sequencing of Serum Small RNAs Identifies Patterns of 5' tRNA Half and YRNA Fragment Expression Associated with Breast Cancer. Biomark. Cancer 2014, 6, 37-47. [CrossRef]

54. Victoria Martinez, B.; Dhahbi, J.M.; Nunez Lopez, Y.O.; Lamperska, K.; Golusinski, P.; Luczewski, L.; Kolenda, T.; Atamna, H.; Spindler, S.R.; Golusinski, W.; et al. Circulating small non-coding RNA signature in head and neck squamous cell carcinoma. Oncotarget 2015, 6, 19246-19263.

55. Yeri, A.; Courtright, A.; Reiman, R.; Carlson, E.; Beecroft, T.; Janss, A.; Siniard, A.; Richholt, R.; Balak, C.; Rozowsky, J.; et al. Total Extracellular Small RNA Profiles from Plasma, Saliva, and Urine of Healthy Subjects. Sci. Rep. 2017, 7, 44061. [CrossRef] [PubMed]

56. Nientiedt, M.; Schmidt, D.; Kristiansen, G.; Muller, S.C.; Ellinger, J. YRNA Expression Profiles are Altered in Clear Cell Renal Cell Carcinoma. Eur. Urol. Focus 2016. [CrossRef] [PubMed]

57. Corrie, P.G.; Marshall, A.; Dunn, J.A.; Middleton, M.R.; Nathan, P.D.; Gore, M.; Davidson, N.; Nicholson, S.; Kelly, C.G.; Marples, M.; et al. Adjuvant bevacizumab in patients with melanoma at high risk of recurrence (AVAST-M): Preplanned interim results from a multicentre, open-label, randomised controlled phase 3 study. Lancet Oncol. 2014, 15, 620-630. [CrossRef]

58. Lamble, S.; Batty, E.; Attar, M.; Buck, D.; Bowden, R.; Lunter, G.; Crook, D.; El-Fahmawi, B.; Piazza, P. Improved workflows for high throughput library preparation using the transposome-based Nextera system. BMC Biotechnol. 2013, 13, 104. [CrossRef] [PubMed]

59. Harrow, J.; Frankish, A.; Gonzalez, J.M.; Tapanari, E.; Diekhans, M.; Kokocinski, F.; Aken, B.L.; Barrell, D.; Zadissa, A.; Searle, S.; et al. GENCODE: The reference human genome annotation for The ENCODE Project. Genome Res. 2012, 22, 1760-1774. [CrossRef] [PubMed]

60. Meyer, L.R.; Zweig, A.S.; Hinrichs, A.S.; Karolchik, D.; Kuhn, R.M.; Wong, M.; Sloan, C.A.; Rosenbloom, K.R.; Roe, G.; Rhead, B.; et al. The UCSC Genome Browser database: Extensions and updates 2013. Nucleic Acids Res. 2013, 41, D64-D69. [CrossRef]

61. Anders, S.; Huber, W. Differential expression analysis for sequence count data. Genome Biol. 2010, 11, R106. [CrossRef]

62. Moret, I.; Sanchez-Izquierdo, D.; Iborra, M.; Tortosa, L.; Navarro-Puche, A.; Nos, P.; Cervera, J.; Beltran, B. Assessing an improved protocol for plasma microRNA extraction. PLoS ONE 2013, 8, e82753. [CrossRef]

63. Lardizabal, M.N.; Nocito, A.L.; Daniele, S.M.; Ornella, L.A.; Palatnik, J.F.; Veggi, L.M. Reference genes for real-time PCR quantification of microRNAs and messenger RNAs in rat models of hepatotoxicity. PLoS ONE 2012, 7, e36323. [CrossRef] 
64. Xiang, M.; Zeng, Y.; Yang, R.; Xu, H.; Chen, Z.; Zhong, J.; Xie, H.; Xu, Y.; Zeng, X. U6 is not a suitable endogenous control for the quantification of circulating microRNAs. Biochem. Biophys. Res. Commun. 2014, 454, 210-214. [CrossRef]

65. Marabita, F.; de Candia, P.; Torri, A.; Tegner, J.; Abrignani, S.; Rossi, R.L. Normalization of circulating microRNA expression data obtained by quantitative real-time RT-PCR. Brief Bioinform. 2016, 17, $204-212$. [CrossRef] [PubMed]

66. DeLong, E.R.; DeLong, D.M.; Clarke-Pearson, D.L. Comparing the areas under two or more correlated receiver operating characteristic curves: A nonparametric approach. Biometrics 1988, 44, 837-845. [CrossRef] [PubMed]

(C) 2019 by the authors. Licensee MDPI, Basel, Switzerland. This article is an open access article distributed under the terms and conditions of the Creative Commons Attribution (CC BY) license (http:/ / creativecommons.org/licenses/by/4.0/). 